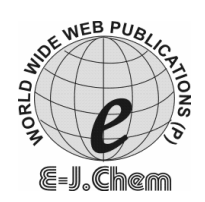

ISSN: 0973-4945; CODEN ECJHAO

E-Journal of Chemistry

2011, 8(1), 19-24

http://www.e-journals.net

\title{
Preparation, Investigation and the Study of the Effect of Mn(II) Complex of Catechol and 2-Aminopyridine on Seed Germination
}

\author{
F.I. EL-MOSHATY, R. S. EL-ZWEAY ${ }^{\S}$, \\ M.M. EL-AJAILY ${ }^{\S *}$ and A. M. JERBOA ${ }^{\S}$ \\ Botany Department, Faculty of Science, Garyounis University, Benghazi, Libya \\ ${ }^{\S}$ Chemistry Department, Faculty of Science, Garyounis University, Benghazi, Libya \\ melagaily@yahoo.com
}

Received 13 March 2008; Accepted 5 June 2008

\begin{abstract}
The formation of mixed ligand complex of Mn(II) with catechol $\left(\mathrm{L}^{1}\right)$ and 2-aminopyridine $\left(\mathrm{L}^{2}\right)$ was determined by elemental analyses $(\mathrm{C}, \mathrm{H}$ and $\mathrm{N}$ ), molar conductance measurement, thermogravimetric analysis, infrared, electronic and electron paramagnetic resonance spectroscopies. The elemental analysis data show the formation of 1:1:1 $\left[\mathrm{M}: \mathrm{L}^{1}: \mathrm{L}^{2}\right]$ complex. The molar conductance measurement shows a non-electrolyte nature. The thermogravimetric analysis data of the complex display the existence of hydrated and coordinated water molecules. The infrared spectral data exhibit the coordination sites that are through $-\mathrm{OH},-\mathrm{C}=\mathrm{N}$ and $-\mathrm{NH}_{2}$ groups. The electronic spectral data display the electronic transitions of the ligands and suggest an octahedral structure for the complex. The electron paramagnetic resonance spectrum of the complex reveals the existence of paramagnetic phenomena and supports its geometrical structure. Seed germination and root length of grass were also assayed under the effect of $\mathrm{MnCl}_{2} \cdot 4 \mathrm{H}_{2} \mathrm{O}$, catechol, 2-aminopyridine and its complex. $\mathrm{Mn}$ (II) salt was the most effective on germination than its complex which possess the high test effect on root length, while the ligands are the least active of all.
\end{abstract}

Keywords: Catechol, 2-Aminopyridine, Complex, Manganese(II) salt, Germination Seed.

\section{Introduction}

Sheng et al. ${ }^{1}$ synthesized and characterized complexes of divalent metal ions $(\mathrm{Mn}, \mathrm{Ni}, \mathrm{Cu}$ and $\mathrm{Zn}$ ) with 1,3-bis (4-methyl-5-imidazol-1-yl)ethylenediamine propan-2-ol. The $\mathrm{Mn}(\mathrm{II})$, $\mathrm{Ni}(\mathrm{II})$ and $\mathrm{Cu}(\mathrm{II})$ complexes exhibited to have an octahedral geometry, meanwhile, the $\mathrm{Zn}$ (II) complex displayed a distorted square-pyramidal coordination structure. 2-Aminopyridine and catechol compounds are bidentate ligands and have a good ability to form 
many transition metal ion complexes ${ }^{2}$. Munzuroglu et $a .^{3}$ reported the effect of metals on seed germination, root elongation and coleoptile and hypocotyl growth in Triticum aestivum and Cucumis sativus.

This report aims to synthesis and characterize Mn(II) mixed ligand complex and to investigate the effect of the ligands, $\mathrm{Mn}$ (II) salt and $\mathrm{Mn}$ (II) complex on seed germination and root length of grass.

\section{Experimental}

\section{Materials}

All chemicals were reagent grade (Merck) including; $\mathrm{MnCl}_{2} \cdot 4 \mathrm{H}_{2} \mathrm{O}$, catechol, 2-aminopyridine, $\mathrm{NH}_{4} \mathrm{OH}, \mathrm{C}_{2} \mathrm{H}_{5} \mathrm{OH}, \mathrm{DMF}$, Double distilled water and grass seeds.

The ligands under investigation have the following structures:<smiles>Oc1ccccc1O</smiles>

$\mathbf{L}^{\mathbf{1}}$ (Catechol)<smiles>Nc1ccccn1</smiles>

$\mathbf{L}^{2}$ (2-aminopyridine)

\section{Preparation of mixed ligand complex}

The mixed ligand complex was prepared by mixing equal amounts $(0.01$ mole $)$ of hot saturated ethanolic solutions of the first ligand $\left(\mathrm{L}^{1}\right)(\mathrm{Catechol} ; 1.10 \mathrm{~g})$ with the same ratio of $\mathrm{MnCl}_{2} \cdot 4 \mathrm{H}_{2} \mathrm{O}$ salt. The mixture was refluxed for one hour and then the second ligand $\left(\mathrm{L}^{2} ; 2-\right.$ aminopyridine; $0.94 \mathrm{~g}$ ) was added in the same ratio to the previous mixture and refluxed for three extra hours. Few drops of ammonia solution were added to adjust the $\mathrm{pH}$ at which the mixed ligand complex even separated. The resulting complex was washed several times with hot ethanol until the filtrate becomes clear, dried in air and then in vacuum over anhydrous $\mathrm{CaCl}_{2}$. The yield ranged from $70-85 \%$. The obtained complex is insoluble in $\mathrm{C}_{2} \mathrm{H}_{5} \mathrm{OH}$ but soluble in DMF solvent. The melting point of the prepared mixed ligand complex was measured and found to be $>360{ }^{\circ} \mathrm{C}$. The dried complex was subjected to elemental and spectroscopic analyses.

Where:

$$
\begin{gathered}
\mathrm{M}^{\mathrm{n}+}+\mathrm{L}_{\mathrm{a}} \rightarrow \mathrm{L}_{\mathrm{a}} \mathrm{M} \\
\mathrm{L}_{\mathrm{a}} \mathrm{M}+\mathrm{L}_{\mathrm{B}} \rightarrow \mathrm{L}_{\mathrm{a}} \mathrm{ML}_{\mathrm{B}}
\end{gathered}
$$

$$
\mathrm{M}^{\mathrm{n}+}=\mathrm{MnCl}_{2} \cdot 4 \mathrm{H}_{2} \mathrm{O} \text { salt, } \mathrm{L}_{\mathrm{a}}=\text { Catechol, } \mathrm{L}_{\mathrm{B}}=2 \text {-aminopyridine }
$$

\section{Measurements}

The synthesized mixed ligand complex was subjected to $(\mathrm{C}, \mathrm{H}$ and $\mathrm{N})$ elemental analyses. The molar conductivity was carried out in DMF solvent using conductivity meter model CMD650 digital, Chemistry Department, Science Faculty, Garyounis University. The thermogravimetric analysis was achieved using Schimadzu thermal analyzer (Japan). The weight loss was measured from ambient temperature to $1000{ }^{\circ} \mathrm{C}$ in rate of $10{ }^{\circ} \mathrm{C} / \mathrm{min}$. The infrared spectrum was obtained by using $\mathrm{KBr}$ disk technique on IFS-25 DPUS/Ir spectrometer (Bruker) in the range of $4000-400 \mathrm{~cm}^{-1}$. The electronic absorption spectrum of the complex was measured in DMF solvent using UV-Vis-NIR3101PC Schimadzu (Japan).The electron paramagnetic resonance spectrum was recorded by using EMX ESR spectrometer (Bruker) 1998Y. All the previous chemical analyses were done at the Micro analytical center, Cairo- University, Egypt. 


\section{Germination assay}

Twenty seeds of wheat were arranged on the filter paper (No. 1) in a Petri dish $(9 \mathrm{~cm})$. The control was treated only with distilled water. Then, two milliliters of each solution and distilled water were added to seeds on the filter paper. The experiments were carried out under natural light and at room temperature. The number of germinated seeds was counted each day for 6 days after which no further seed germination occurred. The length of the roots was measured at the end of the experiment and the elongation of the roots was determined by reference to the elongation of control roots.

\section{Results and Discussion}

\section{Microanalysis}

The elemental analysis data of the mixed ligand complex display the formation of 1:1:1 [M: $\left.\mathrm{L}^{1}: \mathrm{L}^{2}\right]$ ratio. It was found that the theoretical value is in a good agreement with the found ones (calcd: C\% 31.50, found: 30.77, calcd: H\% 6.68, found: 5.74, calcd: N\% 6.68, found: 5.95).

\section{Molar conductivity}

The obtained molar conductance value of the synthesized mixed ligand at $0.40 \mathrm{Ohm}^{-1} \mathrm{~cm}^{2} \mathrm{~mol}^{-1}$ indicates the presence of a non- electrolyte nature ${ }^{4}$.

\section{Thermogravimetric analysis}

The thermogravimetric analysis data of $\left[\mathrm{MnL}^{1} \mathrm{~L}^{2}\left(\mathrm{H}_{2} \mathrm{O}\right)_{2}\right] 7 \mathrm{H}_{2} \mathrm{O}$ complex, (Figure 1) exhibit mass-loss at $31.08 \%$ corresponding to the loss of seven hydrated water molecules at 30$275{ }^{\circ} \mathrm{C}$, meanwhile, the second mass-loss at $13.00 \%$ is due to the loss of two coordinated water molecules at $275-305{ }^{\circ} \mathrm{C}$. At temperature of $305-700{ }^{\circ} \mathrm{C}$, the free ligands were decomposed. The metal oxide residue $(\mathrm{MnO})$ of this complex was appeared at above $700{ }^{\circ} \mathrm{C}$.

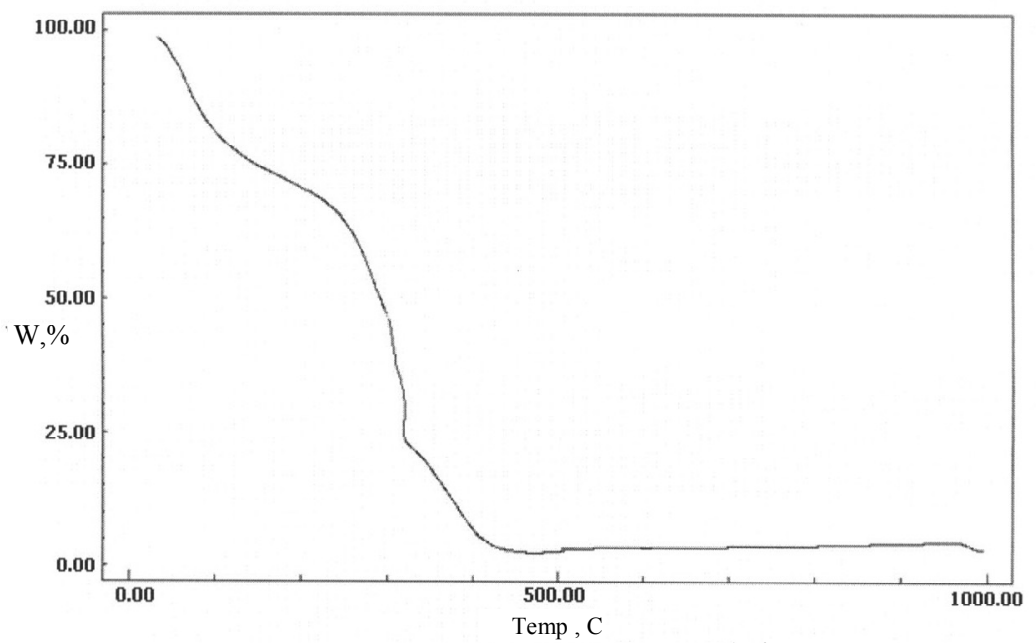

Figure 1. Thermogravimetric analysis of $\mathrm{Mn}(\mathrm{II})-\mathrm{L}^{1} \mathrm{~L}^{2}$ mixed ligand complex

\section{Infrared Spectrum}

The infrared spectral data of $\mathrm{Mn}(\mathrm{II})$ complex displays the absence of the $\mathrm{OH}$ band of the free ligand. The absence of this band indicates that the $\mathrm{OH}$ group is deprotonated and bonded to the metal ion as $-\mathrm{O}^{-}$. On the other hand, the comparison of IR spectra of the ligands under study and its mixed ligand complex indicates that the ligands are principally coordinated to the metal ion and thus acting as bidentate ligands. The band at $1450 \mathrm{~cm}^{-1}$ attributed to the 
attributed to the existence of $(-\mathrm{C}=\mathrm{N})$ group of 2-aminopyridine ligand $\left(\mathrm{L}^{2}\right)$ and this group is shifted to a lower wave number, compared to its original position in the free ligand $\left(1595 \mathrm{~cm}^{-1}\right)$ indicating the participation of the nitrogen atom of the 2-aminopyridine ring in complexation with $\mathrm{Mn}$ (II) ion ${ }^{5}$. The same spectrum exhibits broad band in $3357 \mathrm{~cm}^{-1}$ due to the existence of water molecules in complex ${ }^{6}$. The new bands $621 \mathrm{~cm}^{-1}$ and $482 \mathrm{~cm}^{-1}$ were assigned to $v(\mathrm{M}-\mathrm{O})$ and $v(\mathrm{M}-\mathrm{N})$ vibrations, respectively. The appearance of these bands which are not seen in the free ligands confirmed the involvement of oxygen and nitrogen atoms in chelation with the metal ion ${ }^{7}$ (Figure 2).

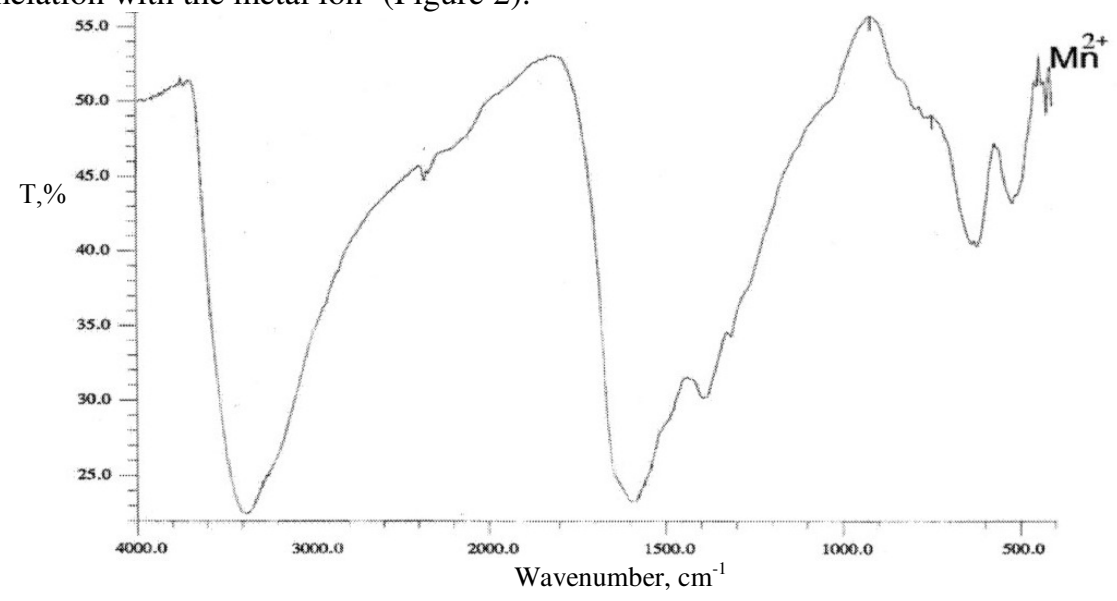

Figure 2. Infrared spectrum of $\mathrm{Mn}(\mathrm{II})-\mathrm{L}^{1} \mathrm{~L}^{2}$ mixed ligand complex

\section{Electronic spectrum}

The electronic absorption spectrum of the complex was measured in DMF solvent Figure 3. Electronic spectral data of $\left[\mathrm{MnL}^{1} \mathrm{~L}^{2}\left(\mathrm{H}_{2} \mathrm{O}\right)_{2}\right] 7 \mathrm{H}_{2} \mathrm{O}$ complex show bands in the range of 305 $591 \mathrm{~nm}\left(32787-16920 \mathrm{~cm}^{-1}\right)$ suggesting the existence of charge transfer and ${ }^{2} \mathrm{~A}_{2} \mathrm{~g} \rightarrow{ }^{2} \mathrm{~T}_{1} \mathrm{~g}$ transitions and an octahedral geometry was proposed for this complex ${ }^{8}$.

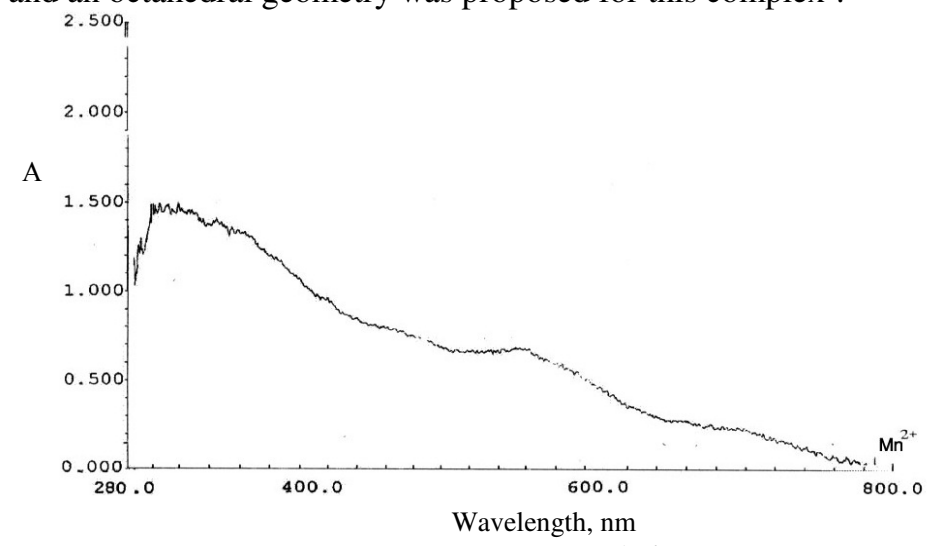

Figure 3. Electronic spectrum of $\mathrm{Mn}(\mathrm{II})-\mathrm{L}^{1} \mathrm{~L}^{2}$ mixed ligand complex

\section{Electron paramagnetic resonance spectrum}

The electron paramagnetic resonance spectrum of the complex shows $\mathrm{g}_{\text {eff }}$ value at 2.125 (Figure 4). The deviation of this value from the ideal value of the free electron (2.0023) 
results from the partial ionic character of the covalent bond between the $\mathrm{Mn}$ (II) ion and mentioned ligands. This value supports the existence of an octahedral configuration ${ }^{9}$.

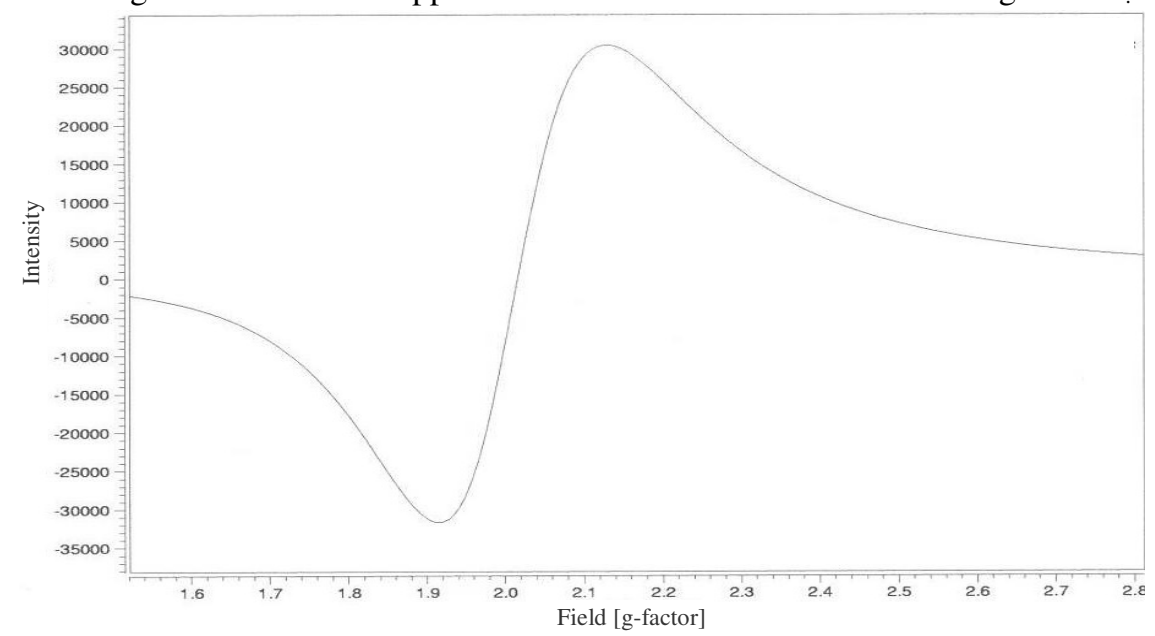

Figure 4. Electron paramagnetic resonance spectrum of $\mathrm{Mn}(\mathrm{II})-\mathrm{L}^{1} \mathrm{~L}^{2}$ mixed ligand complex Seed germination

The effect of different concentrations of $\mathrm{Mn}$ (II) salt, catechol, 2-aminopyridine and $\mathrm{Mn}$ (II) coordination compound were investigated on seed germination and root length (Table 1). Catechol inhibited both seed germination and root growth. The extent of inhibition increased with concentration up to $(0.1 \%)$. No other compounds caused this kind of inhibition even at same concentration applied, except 2-aminopyridine which has a partly inhibition of germination. The $\mathrm{Mn}$ (II) salt has the highest effect on germination than all compounds used, but the effect of $\mathrm{Mn}$ (II) complex exhibited the highest effect on root length.

Table 1. Effect of metal salt, ligands and their complexes on seed germination and root length at 1,2,3 and 4 days

\begin{tabular}{cllllll}
\hline \multirow{2}{*}{ Compounds } & \multicolumn{3}{c}{ Mean of germination } & \multicolumn{3}{c}{ Mean of root length, mm } \\
\cline { 2 - 7 } & $1 \%$ & $0.1 \%$ & $0.01 \%$ & $1 \%$ & $0.1 \%$ & $0.01 \%$ \\
\hline Control & 19.37 & 19.37 & 19.37 & 7.83 & 7.83 & 7.83 \\
$\mathrm{MnCl}_{2} .4 \mathrm{H}_{2} \mathrm{O}$ & 19.49 & 19.43 & 19.87 & 0.00 & 5.16 & 6.50 \\
Catechol & 0.00 & 0.00 & 19.25 & 0.00 & 0.00 & 4.66 \\
2-aminopyridine & 2.37 & 15.75 & 15.37 & 0.00 & 2.83 & 2.67 \\
{$\left[\mathrm{MnL}^{1} \mathrm{~L}^{2}\left(\mathrm{H}_{2} \mathrm{O}\right)_{2}\right] 7 \mathrm{H}_{2} \mathrm{O}$} & 19.56 & 19.00 & 19.43 & 2.83 & 6.67 & 5.33 \\
\hline
\end{tabular}

\section{Conclusion}

From the previous data [elemental analysis, molar conductance measurements, thermogravimetric analysis, infrared, electronic and electron paramagnetic resonance spectra], we propose the following chemical formula for the synthesized mixed ligand complex

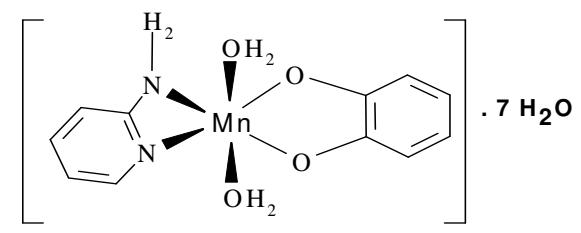

Suggested chemical formula for mixed ligand complex 


\section{References}

1. Sheng L, Chen X M, Yu X L, Zhon Z Y and Ji L N, Polyhedron, 1999, 18, 1927-1933.

2. Lee J D, New Concise in Inorganic Chemistry, ELBS, Van No strand, New York 1991.

3. Munzurglu O and Geckil H, Arch Environ Contam Toxicol., 2004, 43(2), 203-213.

4. Dash D C, Panda A K, Jena P S B Patjoshi and Mohapatra, J Indian Chem Soc., 2002, 79, $48-50$.

5. Venkatalakshmi N and Rajasekharan M V, Indian Academy of Sciences, 1995, 107(4), 327-333.

6. Keypour H S, Salehzadeh and Parish R V, Molecules, 2002, 7, 140-144.

7. Keypour H, Salehzadeh S, Pritchard R G and Parish R V, Transition Met Chem., 1998, 23, 605-607.

8. El-ajaily M M, Maihub A A, Ben-Gwerief S F, Belazi A M and El-zweay R S, Oriental J Chem., 2007, 23(1), 97-104.

9. Ugranker M M and Pradhanada B, Transition Met Chem., 1990, 15, 361. 


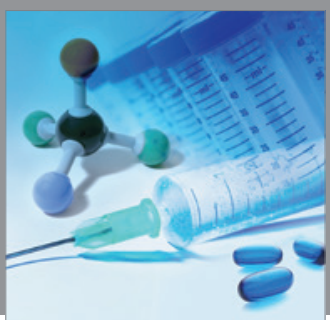

International Journal of

Medicinal Chemistry

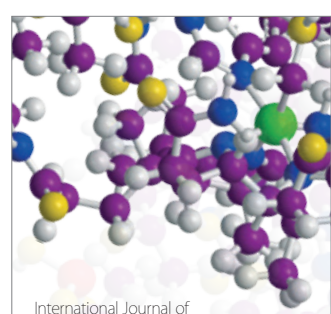

Carbohydrate Chemistry

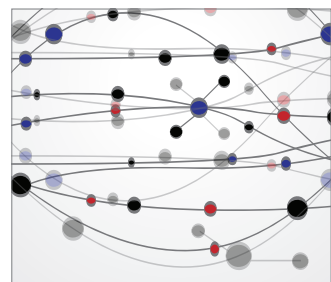

The Scientific World Journal
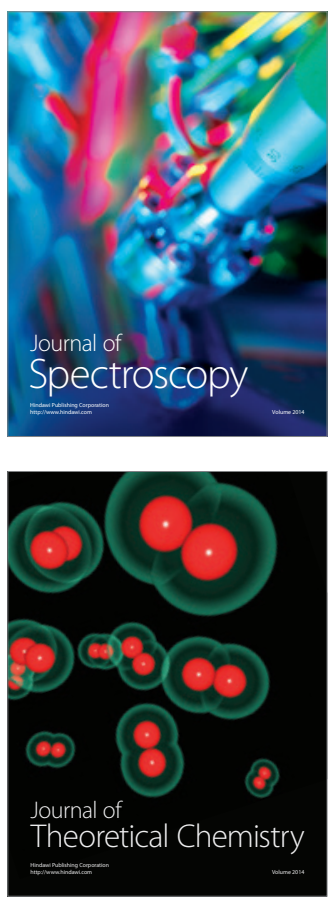
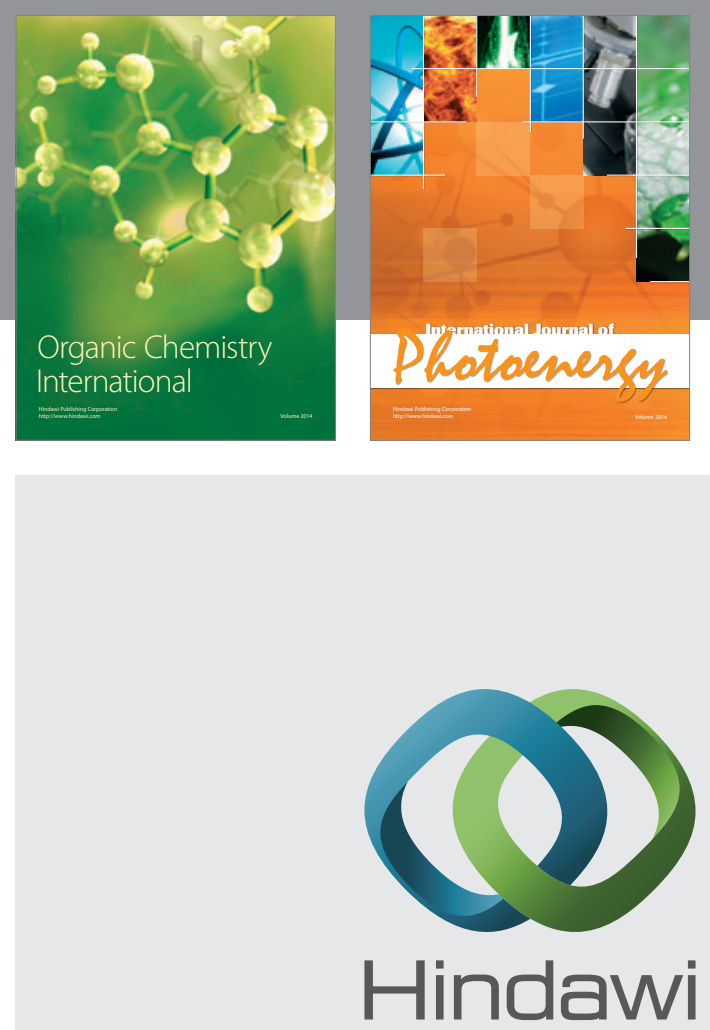

Submit your manuscripts at

http://www.hindawi.com
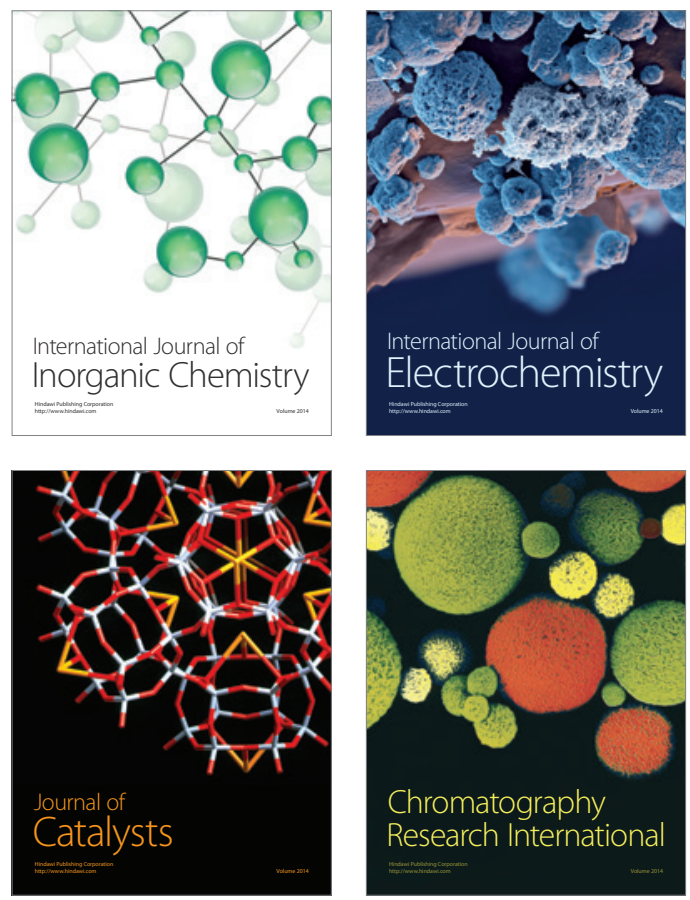
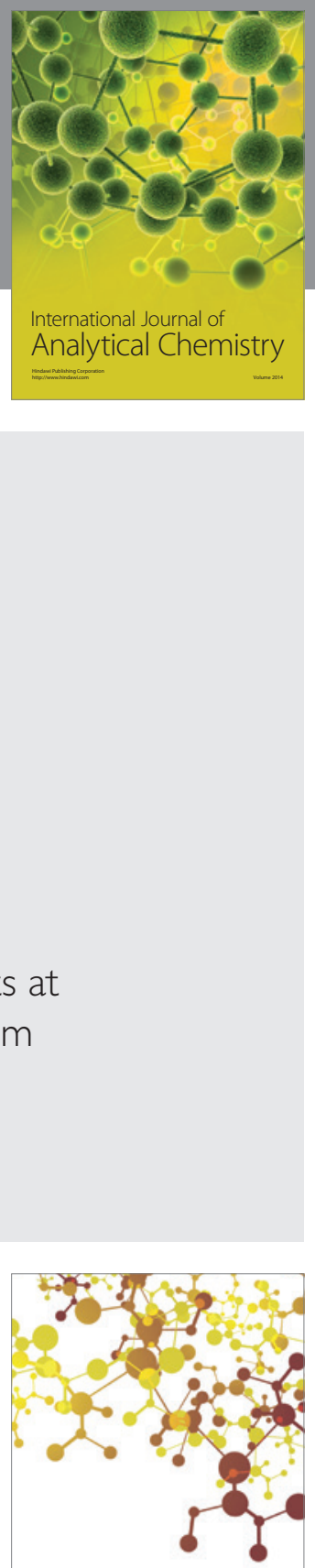

Journal of

Applied Chemistry
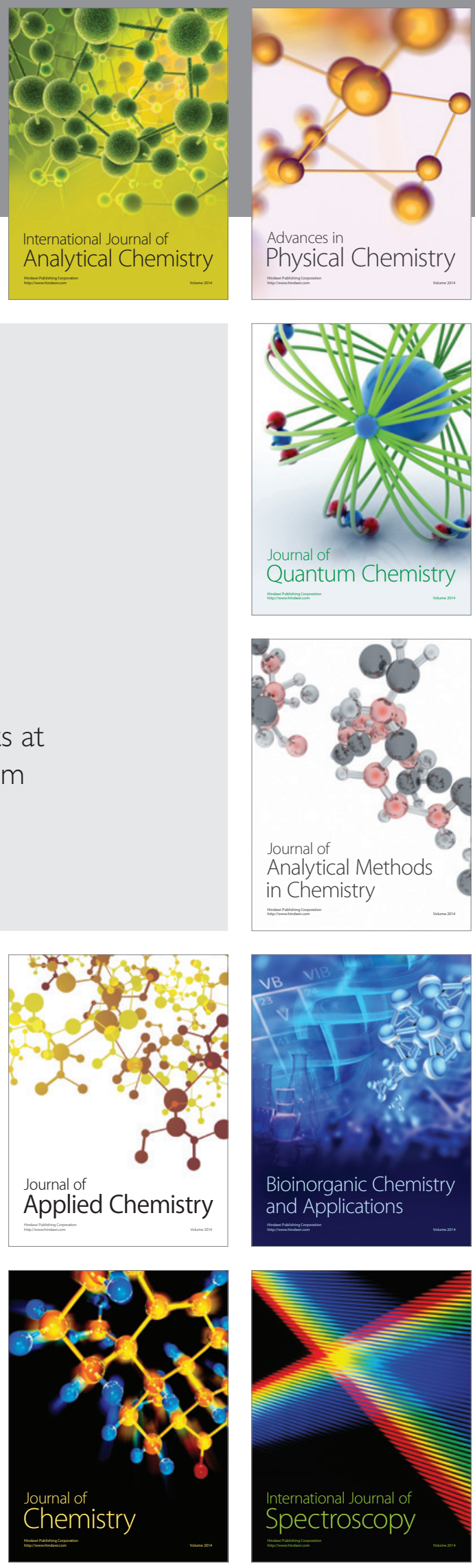